Cellular Physiology
and Biochemistry and Biochemistry Published online: May 09,2016

Accepted: March 22, 2016

This aricle is licensed under the Creative Commons Atribution-NonCommel This article is licensed under the Creative Commons Attribution-NonCommercial-NoDerivatives 4.0 Interna-
tional License (CC BY-NC-ND) (http://www.karger.com/Services/OpenAccessLicense). Usage and distribution for commercial purposes as well as any distribution of modified material requires written permission.

Review

\title{
LOX-1-Mediated Effects on Vascular Cells in Atherosclerosis
}

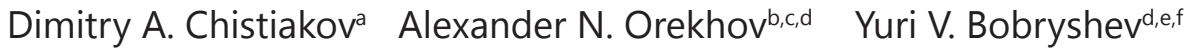

aDepartment of Molecular Genetic Diagnostics and Cell Biology, Division of Laboratory Medicine, Institute of Pediatrics, Research Center for Children's Health, Moscow, Russia; bLaboratory of Angiopathology, Institute of General Pathology and Pathophysiology, Russian Academy of Sciences, Moscow, Russia; 'Department of Biophysics, Biological Faculty, Moscow State University, Moscow, Russia; 'Institute for Atherosclerosis Research, Skolkovo Innovative Center, Moscow, Russia; ${ }^{\circ} F a c u l t y ~ o f$ Medicine, School of Medical Sciences, University of New South Wales, Sydney, NSW, Australia; fSchool $^{2}$ of Medicine, University of Western Sydney, Campbelltown, Australia

\section{Key Words}

Atherosclerosis - Atherogenesis - Arteries - Lectin-like oxidized low-density lipoprotein receptor- $1 \cdot \mathrm{LOX}-1 \cdot$ Oxidized LDL $\bullet$ OxLDL

\begin{abstract}
In healthy arteries, expression of lectin-like oxidized low-density lipoprotein receptor-1 (LOX1 ) is almost undetectable. However, in proatherogenic conditions, LOX-1 is markedly upregulated in vascular cells. In atherosclerosis, LOX-1 appears to be the key scavenger receptor for binding oxidized LDL (oxLDL). Notably, a positive feedback exists between LOX-1 and oxLDL. LOX-1 is involved in mediating of proatherosclerotic effects of oxLDL which result in endothelial dysfunction, proinflammatory recruitment of monocytes into the arterial intima, formation of foam cells, apoptosis of endothelial cells (ECs) and vascular smooth muscle cells (VSMCs), as well as in plaque destabilization and rupture. In this review, we consider effects of the LOX-1/oxLDL axis on several types of vascular cells such as ECs, VSMCs, and macrophages.

\section{Introduction}

Atherosclerotic disease is a chronic disorder that affects arterial vessels of medium or large calibers and has a histological manifestation of plaques enriched with lipids. The entrance of low density lipoproteins (LDL), which are rich of cholesterol, into the intima in athero-prone sites of arteries is accompanied by the adhesion of monocytes to the luminal 
endothelium [1]. Monocytes attracted by the proinflammatory stimuli coming from the inflamed endothelial cells infiltrate the subendothelial layer where they differentiate to macrophages [1]. Macrophages engulf oxidized LDL (oxLDL) but cannot utilize lipids and, eventually, transform into foam cells. Macrophage activation leads to the liberation of proinflammatory cytokines, increased production of reactive oxygen species (ROS), and development of oxidative stress [2].

Macrophages could bind oxLDL through several scavenger receptors (SRs) such as SR-AI, SR-BI, lectin-like oxidized low-density lipoprotein receptor-1 (LOX-1), and CD36 [3]. LOX-1 is a membrane glycoprotein that consists of an $\mathrm{N}$-terminal cytoplasmic domain, a transmembrane domain, an extracellular stalk region (responsible for receptor oligomerization), and C-type lectin-like extracellular domain (responsible for interaction with a ligand) [4]. The receptor comprises 273 amino acid residues. LOX-1 precursor has a molecular weight of $40 \mathrm{kDa}$ that is then glycosylated and processed to a 50-kDa mature form [5].

LOX-1 was also shown to be expressed in endothelial cells (ECs) and smooth muscle cells (VSMCs) [6]. In normal conditions, LOX-1 production is minimal but could be markedly increased under proinflammatory signals. Expression of LOX-1 was found to be initiated by proinflammatory cytokines such as tumor necrosis factor- $\alpha$ (TNF- $\alpha$ ), interleukin- $1 \beta$, interferon- $\gamma$, and vasculoconstrictors including angiotensin II and endothelin-1 [5].

Expression of LOX-1 is especially elevated in advanced plaques [7]. The application of immunohistochemical approach for analysis of LOX-1 expression in human atherosclerotic plaques demonstrated that the LOX-1 immonopositivity is displayed by a large number of intimal cells, even though the intensity of LOX-1 expression markedly varies in different intimal cells [7] (Fig. 1). LOX-1 levels were observed to be up-regulated in intimal VSMCs and in human carotid-plaque macrophages [7]. Genetic deletion of LOX-1 in LDL receptordeficient mice resulted in diminished atherosclerosis whereas overexpression of LOX-1 led to advanced disease $[8,9]$. Therefore, expression of LOX-1 in vascular cells could suggest for its involvement in atherosclerosis.

In addition to oxLDL, numerous ligands such as acetylated forms and other forms of modified lipoproteins, advanced glycation end-products (AGEs), and inflamed platelets could interact with LOX-1 [5]. Furthermore, LOX-1 interacts with high affinity with moderately oxidized LDL rather than massively oxidized LDL [10]. OxLDL binding to LOX-1 results in fast internalization of lipids to the cell while this process could be interrupted by an antibody specific to oxLDL. After internalization, oxLDL becomes unbound of LOX-1, and both molecules retain in distinct areas of the cytoplasm [11]. The major location of LOX1 is caveolae/lipid rafts, and function of LOX-1 is influenced by the cholesterol content of the plasma membrane $[11,12]$. Reduction in membrane cholesterol levels leads to a more random distribution of LOX-1 in the plasma membrane and decreased binding of oxLDL. Therefore, an accumulation of LOX-1 in special membrane compartments is needed for effective binding of oxLDL followed by endocytosis of complexes between LOX-1 and oxLDL [12].

Due to the strong proatherogenic role, marked up-regulation in inflammatory conditions, and effects on ECs, VSMCs, and macrophages (i.e., cells that are crucially involved in atherogenesis), LOX-1 can represent a valuable pharmaceutical target in therapy of cardiovascular diseases. In this brief review, we consider proatherosclerotic effects of LOX-1 on macrophages, ECs, and VSMCs (Fig. 2).

\section{Influence of LOX-1 on Endothelial Cells}

Compared to the other types of vascular cells, LOX-1 exhibits the most robust and broad proatherogenic and proinflammatory effects on arterial ECs because they are primarily exposed to the action of LOX-1. LOX-1 induces endothelial dysfunction and arterial denudation through several mechanisms including proinflammatory activation of ECs, 

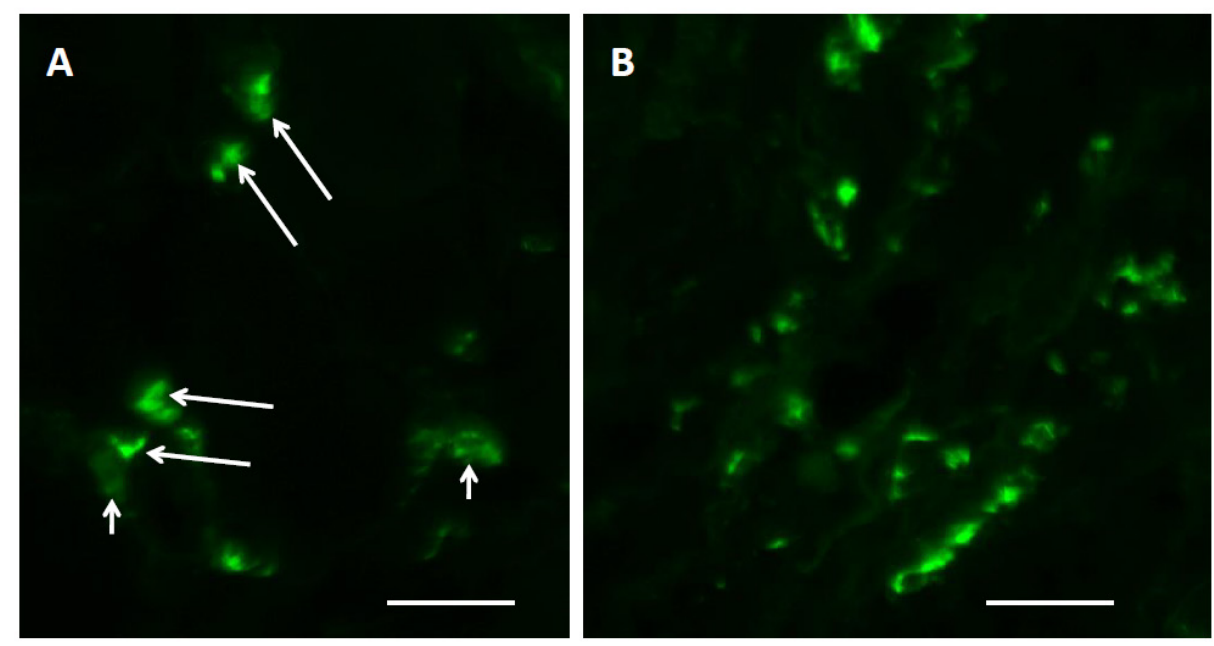

Fig. 1. Typical patterns of LOX-1 expression in human atherosclerotic plaque (A, B). In (A), large arrows show cells that intensely express LOX-1, while small arrows show cells that display a relatively low LOX1 immunopositivity. (A, B): Human aortic specimens; Immunofluorescent analysis utilizing anti-LOX-1 antibody (Abcam; cat\# ab60178) and fluorescein isothiocyanate (FITC) visualization. (A, B): Scale bars = $150 \mu \mathrm{m}$.

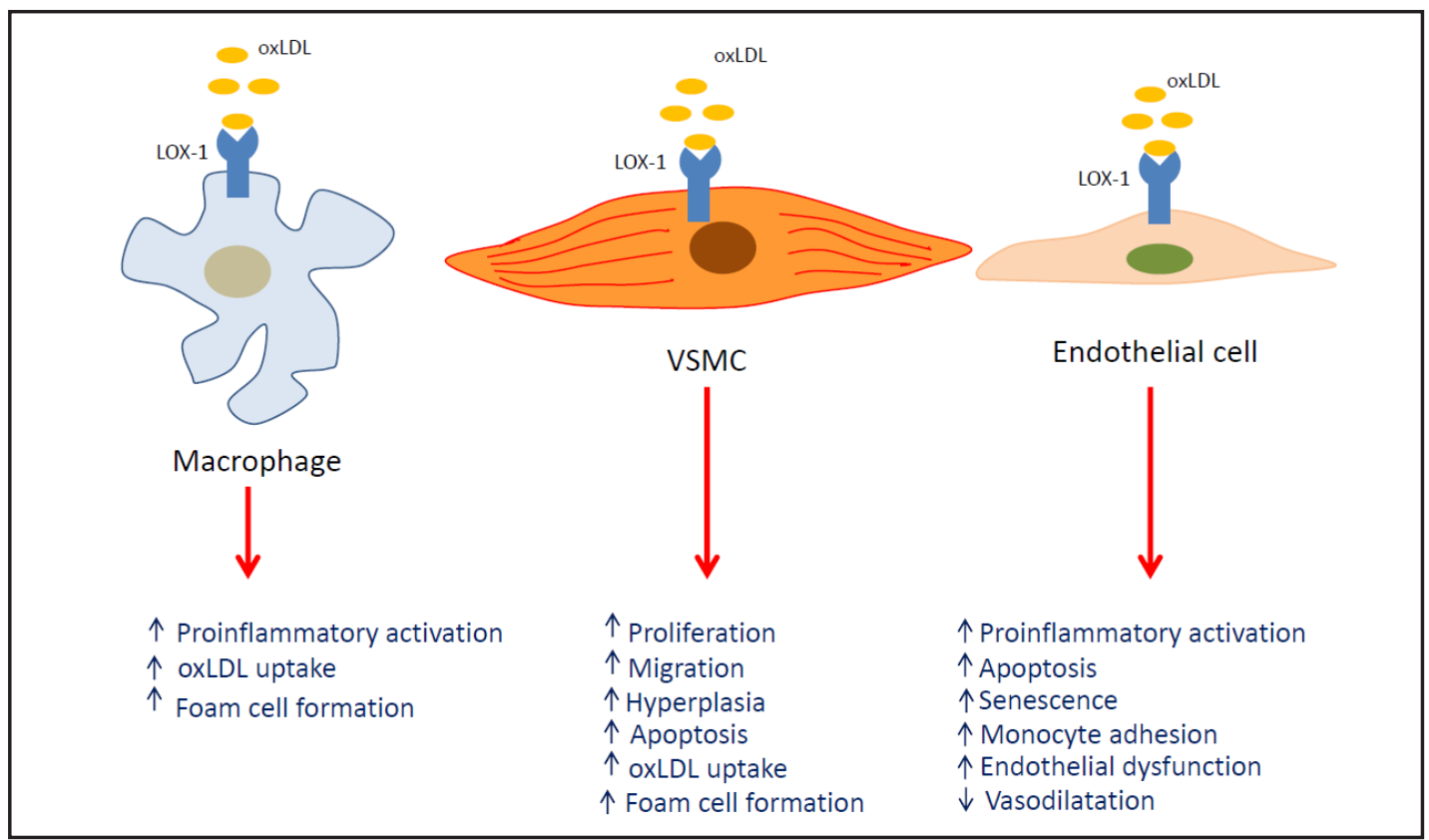

Fig. 2. A summary of proatherosclerotic effects of oxidized LDL (oxLDL) mediated by lectin-like oxLDL receptor-1 (LOX-1) on macrophages, endothelial cells, and vascular smooth muscle cells (VSMCs).

increased endothelial apoptosis and senescence, elevated recruitment of monocytes to ECs, and decreased vascular dilatation (Table 1 [13-24], Fig. 2) [5].

\section{LOX-1 inhibits endothelial NO production}

ECs take up oxLDL mainly via LOX-1 [6]. In ECs, arginase II that decomposes arginine to ornithine and urea controls activity of endothelial nitric oxide synthase (eNOS) by competing for the common substrate L-arginine [25]. LOX-1 mediates stimulatory action of oxLDL on arginase II activation that in turn leads to down-regulation of eNOS activity and impairs endothelial function [26]. In human aortic ECs, oxLDL triggers translocation

\section{KARGER}


Table 1. Proatherogenic activities of LOX-1 in different cell types. Abbreviations: Bax, Bcl2-associated X protein; Bcl2, B-cell lymphoma 2; CCL2, (C-C motif) ligand 2; ICAM-1, intercellular adhesion molecule 1; IL-6, intereukin-6; NAIP1, neuronal inhibitory apoptosis protein 1; NF-kB, nuclear factor kB; TNF- $\alpha$, tumor necrosis factor $\alpha$; VCAM-1, vascular cell adhesion molecule 1

\begin{tabular}{|c|c|c|}
\hline Cell type & LOX-1 effects & References \\
\hline \multirow[t]{2}{*}{$\overline{\mathrm{EC}}$} & $\begin{array}{l}\text { Vasoconstriction through decrease of NO production and availability and increase of } \\
\text { endothelin-1 production } \\
\text { Proinflammatory activation of ECs (induction of chemokine CCL2, IL-6, ICAM-1, VCAM-1, } \\
\text { selectin) } \\
\text { Adhesion of leukocytes to ECs }\end{array}$ & $\begin{array}{l}{[13,14]} \\
{[14-16]} \\
{[16]}\end{array}$ \\
\hline & $\begin{array}{l}\text { EC apoptosis through inhibition of anti-apoptotic factors Bcl2 and NAIP1 and activation } \\
\text { of caspase-3and caspase-9, which degrade Bcl } 2 \text { and NAIP1 } \\
\text { Increased senescence of ECs by inhibition of activation of transcription factor NF-kB, } \\
\text { two-fold increase in Bax/Bcl2 ratio, and 3-fold increase in apoptotic response to TNF- } \alpha\end{array}$ & $\begin{array}{l}{[17]} \\
{[18]}\end{array}$ \\
\hline \multirow[t]{4}{*}{ VSMC } & Induction of proliferation of VSMCs via NF-KB- and JNK-dependent signaling pathways & {$[19]$} \\
\hline & Induction of migration of VSMCs & [9] \\
\hline & Induction of neointimal formation and intimal hyperplasia of VSMCs & {$[20]$} \\
\hline & $\begin{array}{l}\text { Enhanced VSMC apoptosis that is mediated by activation of Bax, caspase-3, and other } \\
\text { apoptotic mediators and leads to plaque destabilization }\end{array}$ & {$[21,22]$} \\
\hline \multirow[t]{2}{*}{ Macrophage } & Stimulation of cholesterol uptake and transformation of macrophages to foam cells & [23] \\
\hline & $\begin{array}{l}\text { Induction of macrophage apoptosis through activation of acid sphingomyelinase/ } \\
\text { ceramide signaling pathway, followed by the endoplasmic reticulum stress }\end{array}$ & {$[24]$} \\
\hline
\end{tabular}

of arginase II from mitochondria to cytosol and back through LOX-1- and rho kinasedependent mechanisms [27]. Mitochondrial processing peptidase was shown to be involved in the activation of arginase II. In ApoE-deficient mice, knockdown of arginase II resulted in decreased plaque progression, reduced oxidative stress, elevated NO production, and improved endothelial function [27]. Indeed, LOX-1 plays an important role in mediating oxLDL-induced endothelial dysfunction.

LOX-1 also mediates oxLDL uptake by ECs by stimulating c-Jun N-terminal kinase (JNK) and protein kinase $\mathrm{C}$ (PKC) $\beta 2$ that leads to the activation of $66-\mathrm{kDa}$ isoform of Shc adaptor proteins (p66Shc) [28]. p66Shc mediates hypertension-associated, cyclic stretch-dependent, endothelial damage [29]. Increased cyclic stretch to the vessel wall leads to endothelial dysfunction through elevated generation of reactive oxygen species (ROS) and reduced NO bioavailability.

\section{LOX-1 induces endothelial apoptosis}

LOX-1 is involved in handling oxLDL-induced apoptosis of ECs that could be prevented by statins (lipid-lowering drugs) and LOX-1-specific inhibitors [30]. This scavenger receptor was shown to down-regulate expression of anti-apoptotic proteins Bcl-2 and neuronal inhibitory apoptotic protein (NAIP) [17]. Moreover, LOX-1 stimulates caspase-3 and -9 that cleave both anti-apoptotic proteins [31].

In addition, the electronegative LDL fraction that actually represents oxidized lipids and unfolded apoB protein, a major protein component of LDL particles, was found to be extensively bound by LOX-1 but not the LDL receptor [32]. This LDL fraction though LOX1 induces apoptosis of ECs by up-regulating expression of several proapoptotic proteins such as tumor necrosis factor (TNF- $\alpha$ ), Bax, and Bcl-2-associated death promoter (Bad) and down-regulating B-cell lymphoma-extralarge (Bcl-xL) [33]. Down-regulation of Akt plays a crucial role in mediating proapoptotic effects of the electronegative LDL fraction on ECs since inhibition of phosphorylation of this kinase is associated with increased expression of LOX1 [17]. Furthermore, electronegative LDL that circulate in blood of smokers were observed to alter the differentiation of endothelial progenitor cells (EPCs) to ECs by suppression of Akt phosphorylation via LOX-1 [34]. Indeed, these data suggest that Akt could be critically involved in modulation of LOX-1 expression. 
LOX-1 induces senescence of ECS

OxLDL were shown to induce senescence of EPCs associated with decreased telomerase activity, diminished proliferation capacity, and ability to form capillary-like structures. Pretreatment of cultivated EPCs with atorvastatin or LOX-1-specific antibody delayed EPC senescence [35]. Compared to early cultures, late passage human umbilical vein ECs (HUVECs) exhibited significant increase in Bax/Bcl2 ratio and 3-fold increase in apoptotic response to TNF- $\alpha$ exposure [18]. Therefore, potential mechanism of the involvement of oxLDL in endothelial senescence may be related to enhanced apoptosis.

LOX1 mediates endothelial inflammatory activation and adhesion of leukocytes to ECS

LOX-1 contributes to the recruitment of monocytes to ECs, a key event in early pathogenesis of atherosclerosis. In ECs, oxLDL was shown to markedly increase production of chemokine (C-C motif) ligand 2 (CCL2) (also known as monocyte chemotactic protein 1 (MCP1) [16]. LOX-1 is crucially involved in induction of oxLDL-dependent expression of CCL2. In addition, LOX-1 mediates oxLDL-dependent stimulation of proinflammatory transcription nuclear factor (NF)- $\mathrm{\kappa B}$ that in turn drives expression of various adhesion molecules [36]. Finally, LOX-1 itself could act as a cell adhesion molecule for monocytes [37].

\section{Influence of LOX-1 on Macrophages}

As mentioned above, macrophages usually express low levels of LOX-1 in the norm. Furthermore, the impact of this receptor in ingestion of oxLDL is too small in healthy arteries [13]. Due to the richness of the arsenal of scavenger receptors, it is not easy to estimate the true input of LOX-1 macrophages. In normal macrophages, the impact of LOX-1 to oxLDL uptake accounts for only 5-10\%. Proinflammatory cytokines stimulate LOX-1 expression and suppress expression of other SRs such as SR-AI and CD36 [3]. In proatherosclerotic conditions, when expression of LOX-1 is increased, the contribution of this receptor to oxLDL uptake by macrophages becomes sufficient and accounts for up to 40\% [23]. Indeed, LOX-1 could play a crucial role in the transformation of macrophages to foam cells [17].

Notably, this receptor is not expressed in monocytes but could be induced in differentiated macrophages [38]. Macrophages could uptake oxLDL LOX-1 after stimulation by various ligands such as oxLDL, lysophosphatidylcholine (LPC) [23], palmitic acid [39], and increased glucose [40]. In non-stimulated macrophages, LOX-1 does not alter oxLDL uptake suggesting for its role for macrophages activated by proinflammatory stimuli.

Monocytes are able to differentiate to dendritic cells (DCs) that play an important role in priming proinflammatory activation of $\mathrm{T}$ cells in atherosclerosis [41]. OxLDL influences maturation and motility of DCs $[42,43]$. In proinflammatory DCs, increased levels of LOX-1 expression were observed. Indeed, LOX-1 significantly activates oxLDL uptake by DCs since using an antibody against LOX-1 decreases uptake of oxLDL by nearly two-fold [44].

\section{Influence of LOX-1 on Vascular Smooth Muscle Cells}

Expression of LOX1 in VSMCs could be stimulated by multiple signals including angiotensin II and oxLDL [45]. Expression of LOX-1 in aorta could be induced by vascular wounding as was shown in a balloon-injury model in rabbits [19] and rats [20]. Moreover, a colocalization LOX-1 and oxLDL was shown in VSMCs in human restenotic plaques thereby indicating the involvement of LOX-1 in oxLDL-dependent VSMC proliferation and restenosis [19].

In cultured rat VSMCs, oxLDL-induced expression of LOX-1 was shown to activate VSMC growth and proliferation (Table 1). After balloon angioplasty, elevated LOX-1 expression was also detected in the neointimal zones of atherosclerotic human coronary arteries. Furthermore, LOX-1 was colocalized with proliferating cell nuclear antigen (PCNA) [19]. 
These findings suggest that LOX-1 mediates oxLDL-dependent VSMC proliferation and is involved in neointima formation after vessel wounding. In apolipoprotein E (apoE)-deficient mice, LOX-1 knockout results in substantial decrease in VSMC proliferation and migration [9]. In LDL receptor (LDLR)-deficient mice, genetic deletion of LOX-1 causes great reduction in intra-plaque collagen deposits [46].

Increased levels of oxLDL were found to stimulate LOX-1 expression in VSMCs followed by VSMC apoptosis [47]. OxLDL-induced apoptosis of arterial VSMCs could therefore be involved in atherosclerotic lesion vulnerability and rupture [5]. In VSMCs, proapoptotic effects of OxLDL were shown to be related to down-regulation of B-cell lymphoma 2 (Bcl2 ), an antiapoptotic protein and up-regulation of proapoptotic regulator Bcl-2-associated $X$ protein (Bax). In human lesions, LOX-1 colocalizes with Bax suggesting for the contribution of LOX-1 in oxLDL-mediated plaque rupture [7].

LPC is known to be a product of hydrolysis of oxLDL mediated by phospholipase A2 [48]. This bioactive lipid exhibits a strong proatherogenic effect. VSMCs exposed to LPC start to express LOX-1 followed by increased uptake of oxLDL [49]. Indeed, LOX-1 could mediate oxLDL-induced transformation of oxLDL to foam cells [50]. In summary, oxLDL up-regulation shows a variety of proatherogenic effects in VSMCs including apoptosis, increased VSMC proliferation and migration, and enhanced foam cell formation, which in turn promotes plaque destabilization, neointima formation, and increase in lipid-rich lesion necrotic core.

\section{Conclusion}

In atherosclerosis, LOX-1 could represent a major mediator of proatherogenic activity of oxLDL in vascular cells especially in ECs. OxLDL-induced up-regulation of LOX-1 results in increased uptake of oxLDL by vascular cells and enhances proatherosclerotic and proinflammatory effects of oxLDL. Indeed, a positive feedback exists between oxLDL and its receptor [3]. An essential progress was achieved in deciphering of signaling pathways mediated by LOX1. However, many puzzles should be resolved to enrich our knowledge of the proatherogenic role of LOX-1. For example, it is interesting to know more about detailed mechanisms by which LOX-1 contributes to oxLDL-induced transformation of VSMCs to foam cells. The oxLDL/LOX-1 axis represents one of the key pathogenic tools in induction of atherosclerosis and therefore represents a promising target for anti-atherosclerotic therapy.

\section{Abbreviations}

AGEs (advanced glycation end-products); Akt (Protein kinase B); apo (apoprotein); apoE (apolipoprotein E); Bad (Bcl-2-associated death promoter); Bax (Bcl-2-associated X protein); Bcl-2 (B-cell lymphoma 2); Bcl-xL (B-cell lymphoma-extralarge); CCL2 (chemokine (C-C motif) ligand 2); DCs (dendritic cells); ECs (endothelial cells); eNOS (endothelial nitric oxide synthase); EPCs (endothelial progenitor cells); HUVECs (human umbilical vein ECs); JNK (c-Jun N-terminal kinase); LDL (low density lipoprotein); LOX-1 (oxidized low-density lipoprotein receptor-1); LPC (lysophosphatidylcholine); MCP1 (chemotactic protein 1); NAIP (neuronal inhibitory apoptotic protein); NF- $\mathrm{BB}$ (nuclear factor- $\kappa \mathrm{B}$ ); oxLDL (oxidized LDL); p66Shc (66-kDa isoform of Shc adaptor proteins); PKB (Protein kinase B); PKC (protein kinase C); ROS (reactive oxygen species); SRs (scavenger receptors); TNF- $\alpha$ (tumor necrosis factor- $\alpha$ ); VSMCs (vascular smooth muscle cells).

\section{Acknowledgements}

This work was supported by the Russian Science Foundation (grant \#14-15-00112), Russian Federation. 


\section{Cellular Physiology Cell Physiol Biochem 2016;38:1851-1859 and Biochemistry Published online: May 09, $2016 \quad \begin{aligned} & \text { DOI: 10.1159/000443123 } \\ & \begin{array}{l}\text { (c) } 2016 \text { The Author(s). Published by S. Karger AG, Basel } \\ \text { www.karger.com/cpb }\end{array}\end{aligned}$ \\ Chistiakov et al.: LOX-1 in Atherosclerosis}

\section{Disclosure Statement}

The authors declare that the research was conducted in the absence of any commercial or financial relationships that could be construed as a potential conflict of interest.

\section{References}

1 Rafiean-Kopaei M, Setorki M, Doudi M, Baradan A, Nasri H: Atherosclerosis: process, indicators, risk factors and new hopes. Int J Prev Med 2014;5:927-946.

2 Libby P: Inflammation in atherosclerosis. Arterioscler Thromb Vasc Biol 2012;32:2045-51.

3 Pirillo A, Norata GD, Catapano AL. LOX-1, oxLDL, and atherosclerosis. Mediators Inflamm 2013;2013:152786.

4 Dunn S, Vohra RS, Murhy JE, Homer-Vanniasinkam S, Walker JH, Ponnanbalam S: The lectin-like oxidized low-density-lipoprotein receptor: a pro-inflammatory factor in vascular disease. Biochem J 2008:409:349355.

5 Xu S, Ogura S, Chen J, Little PJ, Moss J, Liu P: LOX-1 in atherosclerosis: biological functions and pharmacological modifiers. Cell Mol Life Sci 2013;70:2859-2872.

6 Sawamura T, Kume N, Ayoama T, Moriwaki H, Hoshikawa H, Aiba Y, Tanaka T, Miwa S, Katsura Y, Kita T, Masaki T: An endothelial receptor for oxidized low-density lipoprotein. Nature 1997;386:73-77.

7 Kataoka H, Kume N, Miyamoto S, Minami M, Moriwaki H, Murase H, Sawamura T, Masaki T, Hashimoto N, Kita T. Expression of lectin-like oxidized low-density lipoprotein receptor-1 in human atherosclerotic lesions. Circulation 1999;99:3110-3117.

8 Inoue K, Arai Y, Kurihara H, Kita T, Sawamura T: Overexpression of lectin-like oxidized low-density lipoprotein receptor-1 induces intramyocardial vasculopathy in apolipoprotein E-null mice. Circ Res 2005;97:176-184.

9 Mehta JL, Sanada N, Hu CP, Chen J, Dandapat A, Sugawara F, Satoh H, Inoue K, Kawase Y, Jishage K, Suzuki H, Takeya M, Schnackenberg L, Beger P, Hermonat PL, Thomas M, Sawamura T: Deletion of LOX-1 reduces atherogenesis in LDLR knockout mice fed high cholesterol diet. Circ Res 2007;100:1634-1642.

10 Levitan I, Volkov S, Subbaiah PV: Oxidized LDL: diversity, patterns of recognition, and pathophysiology. Antioxid Redox Signal 2010;13:39-75.

11 Twigg MW, Freestone K, Homer-Vanniasinkam S, Ponhambalam S: The LOX-1 Scavenger Receptor and Its Implications in the Treatment of Vascular Disease. Cardiol Res Pract 2012;2012:632408.

12 Matarazzo S, Quitadamo MC, Mango R, Ciccone S, Novelli G, Biocca S: Cholesterol-lowering drugs inhibit lectin-like oxidized low-density lipoprotein-1 receptor function by membrane raft disruption. Mol Pharmacol 2012;82:246-254.

13 Sakurai K, Cominacini L, Garbin U, Fratta Pasini A, Sasaki N, Takuwa Y, Masaki T, Sawamura T: Induction of endothelin-1 production in endothelial cells via co-operative action between CD40 and lectin-like oxidized LDL receptor (LOX-1). J Cardiovasc Pharmacol 2004;44:S173-S180.

14 Lubrano V, Balzan S. Roles of LOX-1 in microvascular dysfunction. Microvasc Res 2016;105:132-140.

15 Kita T, Kume N, Minami M, Hayashida K, Murayama T, Sano H, Moriwaki H, Kataoka H, Nishi E, Horiuchi H, Arai H, Yokode M: Role of oxidized LDL in atherosclerosis. Ann N Y Acad Sci 2001;947:199-205.

16 Li D, Mehta JL: Antisense to LOX-1 inhibits oxidized LDL-mediated upregulation of monocyte chemoattractant protein-1 and monocyte adhesion to human coronary artery endothelial cells. Circulation 2000;101:2889-2895.

17 Li D, Mehta JL: Intracellular signaling of LOX-1 in endothelial cell apoptosis. Circ Res 2009;104:566-568.

18 Khaidakov M, Wang X, Mehta JL: Potential involvement of LOX-1 in functional consequences of endothelial senescence. PLoS On. 2011;6:e20964.

19 Eto H, Miyata M, Kume N, Minami M, Itabe H, Orihara K, Hamasaki S, Biro S, Otsuji Y, Kita T, Tei C: Expression of lectin-like oxidized LDL receptor-1 in smooth muscle cells after vascular injury. Biochem Biophys Res Commun 2006;341:591-598.

20 Hinagata J, Kakutani M, Fujii T, Naruko T, Inoue N, Fujita Y, Mehta JL, Ueda M, Sawamura T: Oxidized LDL receptor LOX-1 is involved in neointimal hyperplasia after balloon arterial injury in a rat model. Cardiovasc Res 2006;69:263-271. 


\section{Cellular Physiology Cell Physiol Biochem 2016;38:1851-1859 \begin{tabular}{l|l} 
DOI: 10.1159/000443123 & $\begin{array}{l}\text { O } 2016 \text { The Author(s). Published by S. Karger AG, Basel } \\
\text { www.karger.com/cpb }\end{array}$
\end{tabular} \\ Chistiakov et al.: LOX-1 in Atherosclerosis}

21 Kume N, Kita T: Apoptosis of vascular cells by oxidized LDL: involvement of caspases and LOX-1 and its implication in atherosclerotic plaque rupture. Circ Res 2004;94:269-270.

22 Ding Z, Wang X, Schnackenberg L, Khaidakov M, Liu S, Singla S, Dai Y, Mehta JL: Regulation of autophagy and apoptosis in response to ox-LDL in vascular smooth muscle cells, and the modulatory effects of the microRNA hsa-let-7 g. Int J Cardiol 2013;168:1378-1385.

23 Schaeffer DF, Riazy M, Parhar KS, Chen JH, Duronio V, Sawamura T, Steinbrecher UP: LOX-1 augments oxLDL uptake by lysoPC-stimulated murine macrophages but is not required for oxLDL clearance from plasma. J Lipid Res 2009;50:1676-1684.

24 Zhao M, Pan W, Shi RZ, Bai YP, You BY, Zhang K, Fu QM, Schuchman EH, He XX, Zhang GG: Acid sphingomyelinase mediates oxidized-LDL induced apoptosis in macrophage via endoplasmic reticulum stress. J Atheroscler Thromb DOI:10.5551/jat.32383.

25 Li H, Meininger CJ, Hawker JR Jr, Haynes TE, Kepka-Lenhart D, Mistry SK, Morris SM Jr, Wu G: Regulatory role of arginase I and II in nitric oxide, polyamine, and proline syntheses in endothelial cells. Am J Physiol Endocrinol Metab 2001;280:E75-E82.

26 Ryoo S, Bhunia A, Chang F, Shoukas A, Berkowitz DE, Romer LH: OxLDL-dependent activation of arginase II is dependent on the LOX-1 receptor and downstream RhoA signaling. Atherosclerosis 2011;214:279-287.

27 Pandey D, Bhunia A, Oh YJ, Chang F, Bergman Y, Kim JH, Serbo J, Boronina TN, Cole RN, Van Eyk J, Remaley AT, Berkowitz DE, Romer LH: OxLDL triggers retrograde translocation of arginase2 in aortic endothelial cells via ROCK and mitochondrial processing peptidase. Circ Res 2014;115:450-459.

28 Shi Y, Cosentino F, Camici GG, Akhmedov A, Vanhoutte PM, Tanner FC, Lüscher TF: Oxidized low-density lipoprotein activates p66Shc via lectin-like oxidized low-density lipoprotein receptor-1, protein kinase C-beta, and c-Jun N-terminal kinase kinase in human endothelial cells. Arterioscler Thromb Vasc Biol 2011;31:2090-2097.

29 Spescha RD, Glanzmann M, Simic B, Witassek F, Keller S, Akhmedov A, Tanner FC, Lüscher TF, Camici GG: Adaptor protein p66(Shc) mediates hypertension-associated, cyclic stretch-dependent, endothelial damage. Hypertension 2014;64:347-353.

30 Li DY, Chen HJ, Mehta JL: Statins inhibit oxidized-LDL-mediated LOX-1 expression, uptake of oxidized-LDL and reduction in PKB phosphorylation. Cardiovasc Res 2001;52:130-135.

31 Chen J, Mehta JL, Haider N, Zhang X, Narula J, Li D: Role of caspases in Ox-LDL-induced apoptotic cascade in human coronary artery endothelial cells. Circ Res 2004;94:370-376.

32 Hamilton RT, Asatryan L, Nilsen JT, Isas JM, Gallaher TK, Sawamura T, Hsiai TK: LDL protein nitration: implication for LDL protein unfolding. Arch Biochem Biophys 2008;479:1-14.

33 Lu J, Yang JH, Burns AR, Chen HH, Tang D, Walterscheid JP, Suzuki S, Yang CY, Sawamura T, Chen CH: Mediation of electronegative low-density lipoprotein signaling by LOX-1: a possible mechanism of endothelial apoptosis. Circ Res 2009;104:619-627.

34 Tang D, Lu J, Walterscheid JP, Chen HH, Engler DA, Sawamura T, Chang PY, Safi HJ, Yang CY, Chen CH: Electronegative LDL circulating in smokers impairs endothelial progenitor cell differentiation by inhibiting Akt phosphorylation via LOX-1. J Lipid Res 2008;49:33-47.

35 Imanishi T, Hano T, Sawamura T, Nishio I: Oxidized low-density lipoprotein induces endothelial progenitor cell senescence, leading to cellular dysfunction. Clin Exp Pharmacol Physiol 2004;31:407-413.

36 Chen JW, Zhou SB, Tan ZM: Aspirin and pravastatin reduce lectin-like oxidized low density lipoprotein receptor-1 expression, adhesion molecules and oxidative stress in human coronary artery endothelial cells. Chin Med J (Engl) 2010;123:1553-1556.

37 Honjo M, Nakamura K, Yamashiro K, Kiryu J, Tanihara H, McEvoy LM, Honda Y, Butcher EC, Masaki T, Sawamura T: Lectin-like oxidized LDL receptor-1 is a cell-adhesion molecule involved in endotoxininduced inflammation. Proc Natl Acad Sci USA 2003;100:1274-1279.

38 Moriwaki H, Kume N, Kataoka H, Murase T, Nishi E, Sawamura T, Masaki T, Kita T: Expression of lectin-like oxidized low density lipoprotein receptor-1 in human and murine macrophages: upregulated expression by TNF-alpha. FEBS Lett 1998;440:29-32.

39 Ishiyama J, Taguchi R, Yamamoto A, Murakami K: Palmitic acid enhances lectin-like oxidized LDL receptor (LOX-1) expression and promotes uptake of oxidized LDL in macrophage cells. Atherosclerosis 2010;209:118-124.

40 Li L, Sawamura T, Renier G: Glucose enhances human macrophage LOX-1 expression: role for LOX-1 in glucose-induced macrophage foam cell formation. Circ Res 2004;94:892-901. 


\section{Cellular Physiology Cell Physiol Biochem 2016;38:1851-1859 \begin{tabular}{l|l} 
DOI: 10.1159/000443123 & $\begin{array}{l}\text { O 2016 The Author(s). Published by S. Karger AG, Basel } \\
\text { www.karger.com/cpb }\end{array}$
\end{tabular} \\ Chistiakov et al.: LOX-1 in Atherosclerosis}

41 Bobryshev YV. Dendritic cells in atherosclerosis: current status of the problem and clinical relevance. Eur Heart J 2005;26:1700-1704.

42 Perrin-Cocon L, Coutant F, Agaugué S, Deforges S, André P, Lotteau V: Oxidized low-density lipoprotein promotes mature dendritic cell transition from differentiating monocyte. J Immunol 2001;167:3785-3791.

43 Nickel T, Hanssen H, Sisic Z, Pfeiler S, Summo C, Schmauss D, Hoster E, Weis M: Immunoregulatory effects of the flavonol quercetin in vitro and in vivo. Eur J Nutr 2011;50:163-172.

44 Nickel T, Schmauss D, Hanssen H, Sicic Z, Krebs B, Jankl S, Summo C, Fraunberger P, Walli AK, Pfeiler S, Weis M: oxLDL uptake by dendritic cells induces upregulation of scavenger-receptors, maturation and differentiation. Atherosclerosis 2009;205:442-450.

45 Sun Y, Chen X: Ox-LDL-induced LOX-1 expression in vascular smooth muscle cells: role of reactive oxygen species. Fundam Clin Pharmacol 2011;25:572-579.

46 Hu C, Dandapat A, Sun L, Chen J, Marwali MR, Romeo F, Sawamura T, Mehta JL: LOX-1 deletion decreases collagen accumulation in atherosclerotic plaque in low-density lipoprotein receptor knockout mice fed a high-cholesterol diet. Cardiovasc Res 2008;79:287-293.

47 Kataoka H, Kume N, Miyamoto S, Minami M, Morimoto M, Hayashida K, Hashimoto N, Kita T: Oxidized LDL modulates Bax/Bcl-2 through the lectin-like Ox-LDL receptor-1 in vascular smooth muscle cells. Arterioscler Thromb Vasc Biol 2001;21:955-960.

48 Murugesan G, Fox PL: Role of lysophosphatidylcholine in the inhibition of endothelial cell motility by oxidized low density lipoprotein. J Clin Invest 1996;97:2736-2744.

49 Aoyama T, Chen M, Fujiwara H, Masaki T, Sawamura T: LOX-1 mediates lysophosphatidylcholine-induced oxidized LDL uptake in smooth muscle cells. FEBS Lett 2000;467:217-220.

50 Klouche M, Rose-John S, Schmiedt W, Bhakdi S: Enzymatically degraded, nonoxidized LDL induces human vascular smooth muscle cell activation, foam cell transformation, and proliferation. Circulation 2000;101:1799-1805. 